\title{
ANALISIS EFEK GERHANA MATAHARI TOTAL 9 MARET 2016 TERHADAP KANDUNGAN TOTAL ELEKTRON IONOSFER
}

\author{
Afrita Ariani ${ }^{1}$, Usman Malik ${ }^{1}{ }^{1}$, Asnawi Husin ${ }^{2}$ \\ ${ }^{1}$ Jurusan Fisika Fakultas Matematika dan Ilmu Pengetahuan Alam Universitas Riau \\ ${ }^{2}$ Pusat Sains Antariksa LAPAN, Bandung \\ *E-mail korespondensi: usman.malik @lecturer.unri.ac.id
}

\begin{abstract}
Total elektron contant in ionosphere is affected by several fastors, local time, solar aktivities, geomagnetic disturbance, geographical latitude and longitude. This researh aims to observase level variation of total electron contant during solar eclipse over Indonesia on 9 March 2016. We analyzed GPS data from two GPS stations in different locations with different sun observation geographical latitude and longitude, the locations were Sulawesi station (CAMP) and Maluku station (CAMB). The method used in this research, was data interpretation method computationally, the whole data analyzed using matlab software R2008a. The values of daily TEC range from 20 TECU till $30 \mathrm{TECU}$. Although the value of TEC when solar total eclipse range from 10n TECU untill 20 TECU. The percentage of decreasing value of TEC when total solar eclipse than the daily value of TEC. Decreasing of TEC value between 20\%-40\%.
\end{abstract}

Keywords: TEC, solar radiation, GPS, Ionosphere

\begin{abstract}
ABSTRAK
Total elektron contant (TEC) di ionosfer dipengaruhi oleh beberapa faktor, diantaranya waktu lokal, aktivitas matahari, gangguan geomagnet, lintang dan bujur geografis. Penelitian ini dilakukan untuk mengetahui perubahan nilai TEC di ionosfer selama gerhana matahari total yang melintasi Indonesia pada tanggal 9 Maret 2016. Data yang digunakan adalah data pengamatan GPS-TEC pada dua stasiun di lokasi yang mengalami gerhana matahari dengan nilai lintang dan bujur geografis yang berbeda. Stasiun yang digunakan adalah Stasiun Sulawesi (CAMP) dan Stasiun Maluku (CAMB). Metode yang digunakan dalam penelitian ini adalah metode interpretasi data secara komputasi, seтиa data yang diperoleh dianalisis menggunakan sofware Matlab R2008@. Nilai TEC harian berkisar antara 20 TECU sanpai dengan 30 TECU, sedangkan nilai TEC pada saat GMT berkisar antara 10 TECU sampai dengan 20 TECU. Perentase penurunan nilai TEC saat GMT dibandingkan nilai TEC harian. Besarnya persentase penurunan nilai TEC berkisar antara $20 \%-40 \%$.
\end{abstract}

Kata kunci: TEC, Radiasi matahari, GPS, Ionosfer

Diterima 20-02-2020| Disetujui 29-02-2020| Dipublikasi 31-03-2020

\section{PENDAHULUAN}

Gerhana matahari total (GMT) merupakan fenomena astronomi dan jarang terjadi termasuk di Indonesia. Fenomena GMT yang baru terjadi pada tanggal 9 Maret 2016, yang sebagian besar melintasi daratan wilayah indonesia. Fenomena ini sangat dinanti oleh masyarakat luas, khususnya kalangan ilmiah dan pendidikan.
Fenomena GMT juga memberikan dampak terhadap lapisan atmosfer bumi. Fenomena GMT mengakibatkan penurunan radiasi matahari secara langsung akan meyebabkan penurunan temperatur sehingga kelembapan meningkat. Akibatnya ketidakstabilan dalam lapisan batas atmosfer sehingga akan berpengaruh terhadap perubahan angina [1].

Selain itu, gerhana matahari akan mempengaruhi kandungan elektron di ionosfer 
akibat berkurangnya radiasi matahari ke ionosfer. Kandungan elektron di ionosfer dipengaruhi oleh beberapa faktor antara lain lintang dan bujur geografis, waktu lokal, aktivitas matahari, dan gangguan geomagnet. Pengaruh gerhana matahari terhadap ionosfer dapat berlangsung selama beberapa jam setelah totalitas terbesar [2].

Data GPS telah banyak dimanfaatkan untuk penelitian mengenai gangguan ionosfer yang diakibatkan oleh alam maupun buatan, seperti gempabumi . Penelitian ini dilakukan untuk mengetahui efek gerhana matahari terhadap ionosfer berdasarkan data Total Electron Content (TEC) / kandungan total elektron yang diperoleh dari data GPS. Data yang dipergunakan adalah data satu hari sebelum, saat dan sesudah kejadian. Data diambil dari dua stasiun yang terletak di lokasi yang mengalami gerhana matahari dengan magnitudo berbeda. Nilai TEC diturunkan dari data pengamatan GPS stasiun tetap jaring kontrol atau dikenal dengan Contimous Operating Reference Station (CORS) dan Badam Informasi Geospasial BIG [3].

\section{METODE PENELITIAN}

Metodelogi yang digunakan adalah metodelogi interverensi data. Data yang digunakan adalah data sekunder dari pengamatan GPS pada tanggal 8 Maret, 9 Maret dan 10 Maret 2016. Data GPS yang digunakan data dari stasiun CAMB dan CAMP, satu hari sebelum, saat, dan sesudah gerhana. Data GPS dalam format RINEX kemudian diubah dalam bentuk Ms. Excel.

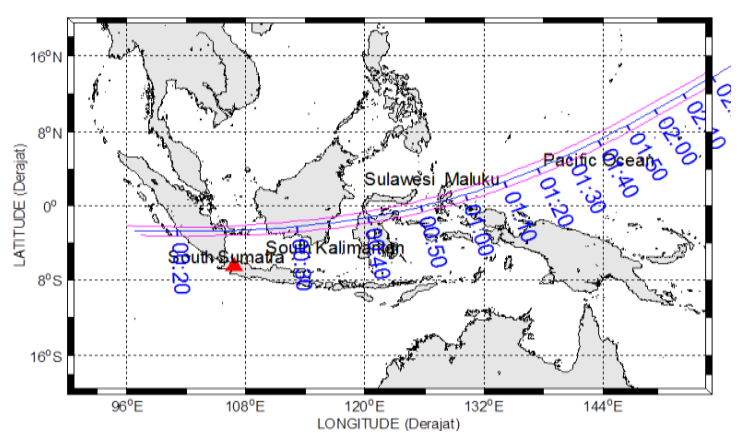

Gambar 1. Lintasan GMT 9 Maret 2016.
Peta lintasan gerhana matahari dan lokasi stasiun yang digunakan dalam penelitian ini di tunjukkan pada Gambar 1.

Gambar 1 menunjukkan urutan kejadian gelap terang total yang melintasi beberapa pulau di indonesia (umbra). Sedangkan Gambar 2 menunjukkan letak stasiun CORS dari BIG yang digunakan dalam pengamatan efek GMT pada total elektron contant(TEC), dari data GPS dilakukan penurunan nilai TEC persatelit. Analisis kecendrungan perubahan nilai TEC satu hari sebelum, saat terjadi gerhana dan sesudah gerhana matahari pada jam puncak gerhana dilakukan untuk melihat efek gerhana di ionosfer.

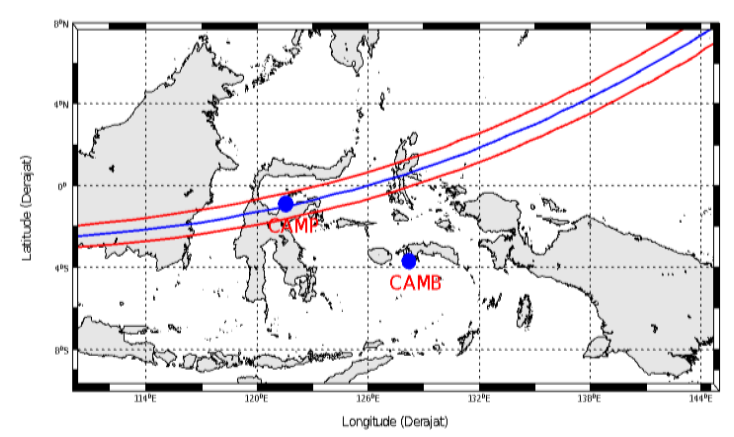

Gambar 2. Posisi stasiun pada lintasan GMT 9 Maret 2016.

Fenomena GMT ini melintasi beberapa daerah daerah daratan Indonesia. Fenomena GMT di Indonesia melintasi Pulau Sumatera, Kalimantan, Maluku, Selawesi dan berakhir di Lautan Fasifik.

Posisi stasiun CAMP tepat berada didalam daerah lintasan fenomena GMT, sedangkan stasiun CAMB berada di luar daerah lintasan fenomena GMT. Hal ini bertujuan sebagai perbanding antara nilai TEC pada stasiun CAMP dengan stasiun CAMB pada saat terjadi GMT. Lokasi penelitian dilakukan pada stasiun pengamatan GPS di daerah yang dilintasi oleh fenomena GMT. Berikut adalah nama - nama stasiun pada tanggal 8 maret 2016, tanggal 9 maret 2016, tanggal 10 maret 2016.

Dua stasiun pengamatan tersebut memiliki nilai bujur geografis dan lintang geografi yang berbeda - beda. Kedua stasiun ini berada pada daerah yang dilintasi oleh fenomena GMT, 
salah satu dari stasiun tersebut berada tepat pada daerah yangr lintasi oleh fenomena GMT 9 Maret 2016.

Data yang digunakan dalam penelitian ini merupakan data pengamatan GPS dalam bentuk data RINEX, (Receiver Independent Exchange Format), yang merupakan format standar data GPS. Data TEC diturunkan dari data RINEX dengan menggunakan perangkat lunak ilmiah (scientific software) di Pusat Sains Antariksa, LAPAN. Kemudian, dilakukan pengolahan data dengan menggunakan Matlab. Menghitung nilai TEC dalam waktu 24 jam dari beberapa satelit yang terekam dari dua stasiun pengamatan menggunakan Persamaan (1).

Untuk menentukan persentase pengurangan nilai TEC pada saat GMT dapat menggunakan persamaan 2.4. \% DTEC merupkan persentasi perbedaan TEC GMT dengan TEC latar belakang harian. TEC latar belakang harian merupakan median dari TEC 8 Maret dan TEC 10 Maret 2016.

\% DTEC $=\frac{\text { TEG saat GMT-TECinarian }}{\text { TECharian }} x 100 \%$

\section{HASIL DAN PEMBAHASAN}

Data pengamatan yang diambil dari dua stasiun yang berbeda untuk mengetahui perbandingan nilai TEC pada stasiun lintasan dan nilai TEC di luar lintasan GMT 9 Maret 2016. Nilai TEC di stasiun pengamatan GPS saat terjadi Gerhana dibandingkan dengan nilai TEC pada satu hari sebelum dan pada satu hari sesudah gerhana matahari total. Analisis dilakukan pada 00.00 UT sampai dengan 03.00 UT. Stasiun CAMP berada di jalur lintasan GMT 9 Maret 2016. TEC GMT dapat dilihat pada Gambar 3 (a), TEC sebelum GMT pada Gambar 3 (b) dan TEC sesudah GMT pada Gambar 3 (c).

Hasil dari penelitian yang telah dilakukan dapat disimpulkan bahwa efek GMT 9 Maret 2016 tidak mempengaruhi lapisan ionosfer secara signifikan, hal ini dikarenakan waktu terjadinya GMT hanya beberapa menit. Namun, TEC cenderung memiliki mode fluktuasi yang sama berdasarkan jam nya.
Pada jam 05.00 -10.00 UT, TEC berada pada nilai maksimal dan pada 20.00-00.00 UT, TEC berada pada nilai minimum. Efek GMT pada TEC dapat dilihat persatelit, seperti yang di tunjukkan Gambar 4, lintasan dari beberapa satelit GPS yang jauh atau dekat dengan lintasan GMT. Stasiun pengamatan CAMP berada pada daerah yang dilintasi oleh fenomena GMT seperti yang dijelaskan sebelumya. Pada data pengamatan stasiun CAMP terekam sebanyak 31 satelit yang melewati lintasan GMT 9 Maret 2016 [4].

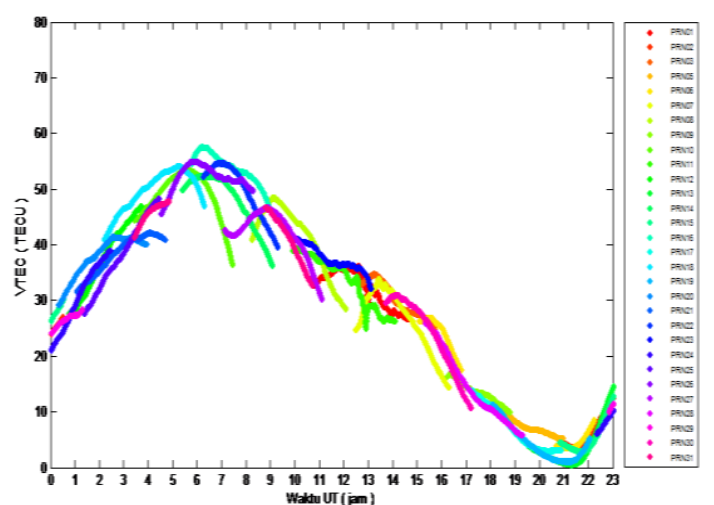

(a)

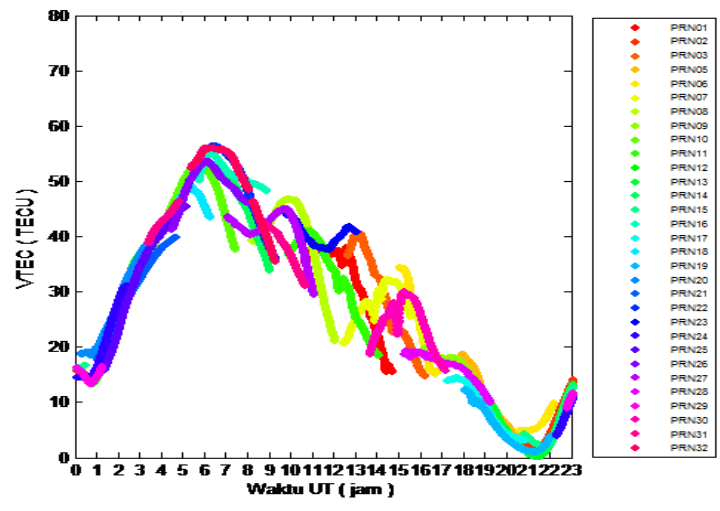

(b)

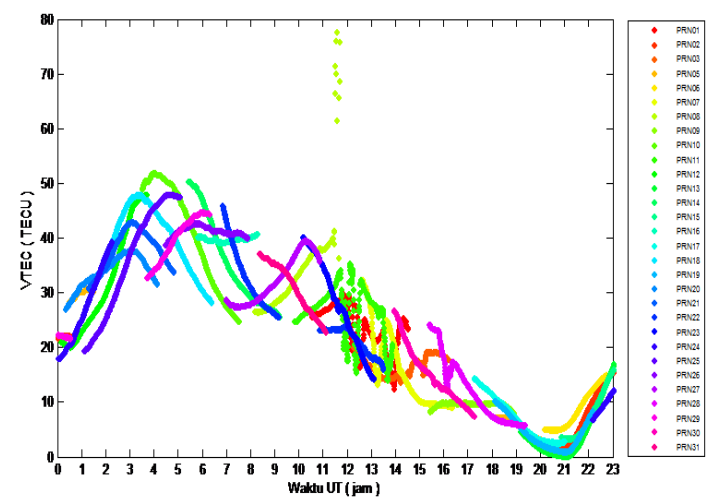

(c)

Gambar 3. Nilai TEC pada tanggal (a) 8, (b) 9, dan (c) 10 Maret 2016. 


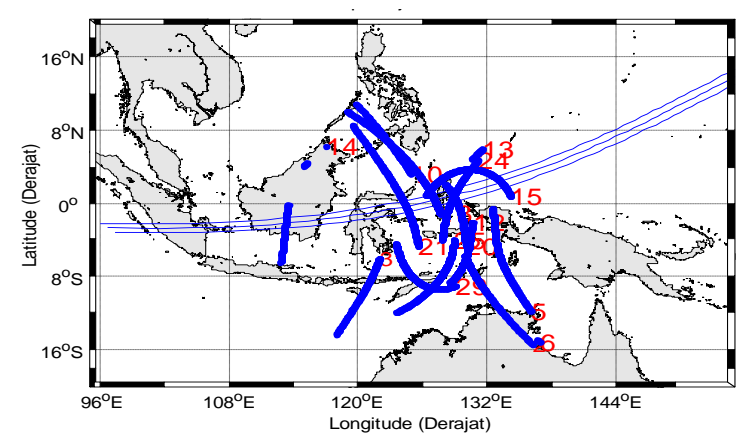

Gambar 4. Satelit - satelit GPS yang melintas terekam oleh antena GPS melalui stasiun CAMP.

Satelit 12 merupakan salah satu satelit yang melewati lintasan GMT yang terekam oleh stasiun pengamatan CAMP. Lintasan satelit 12 di mulai dari bawah lintasan GMT dan berakhir di atas lintasan GMT.

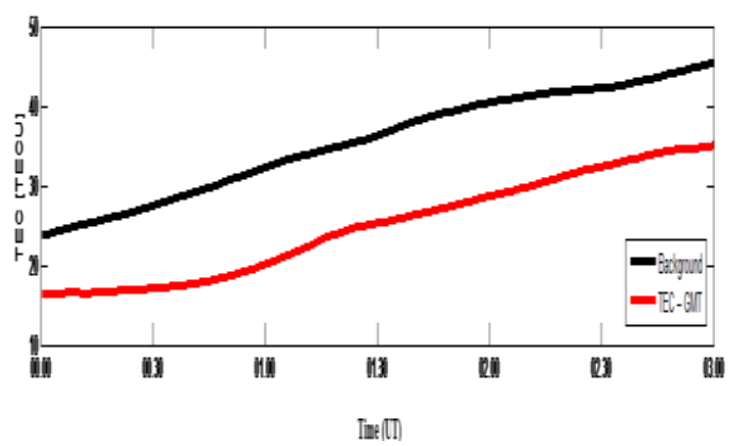

(a)

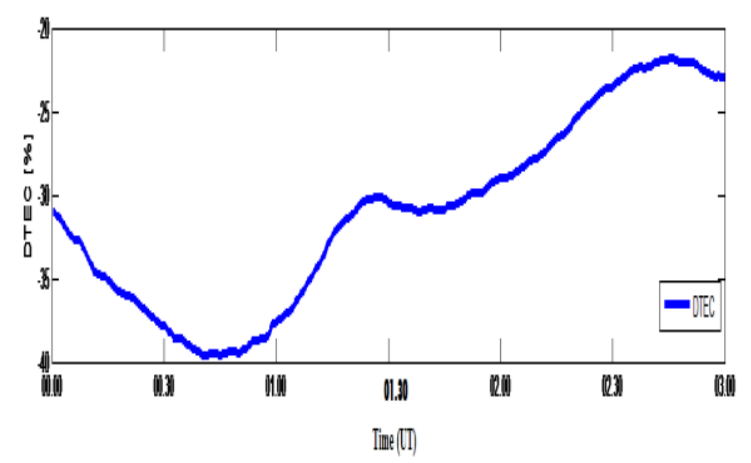

(b)

Gambar 5. (a) Perbandingan nilai TEC GMT dan TEC harian, (b) persentase penurunan nilai TEC GMT terekam oleh satelit 12 .

Gambar 5 (a) menjelaskan bahwa nilai TEC GMT mengalami penurunan dari pada nilai TEC harian. Nilai TEC harian berkisar antara 20 TECU sanpai dengan 30 TECU, sedangkan nilai TEC pada saat GMT berkisar antara 10 TECU sampai dengan 20 TECU. Gambar 5 (b) menunjukkan persentase penurunan nilai TEC saat GMT dibandingkan nilai TEC harian. Besarnya persentase penurunan nilai TEC berkisar antara $20 \%-40 \%$.

Satelit 31 merupakan salah satu satelit yang terekam oleh stasiun pengamatan CAMP dan satelit yang tidak melintasi lintasan GMT 9 Maret 2016. Untuk melihat efek GMT terhadap ionesfer maka akan dibandingkan nilai TEC pada satelit yang melewati lintasa GMT dengan nilai TEC pada satelit yang berada di luar lintasa GMT 9 maret 2016 [5].

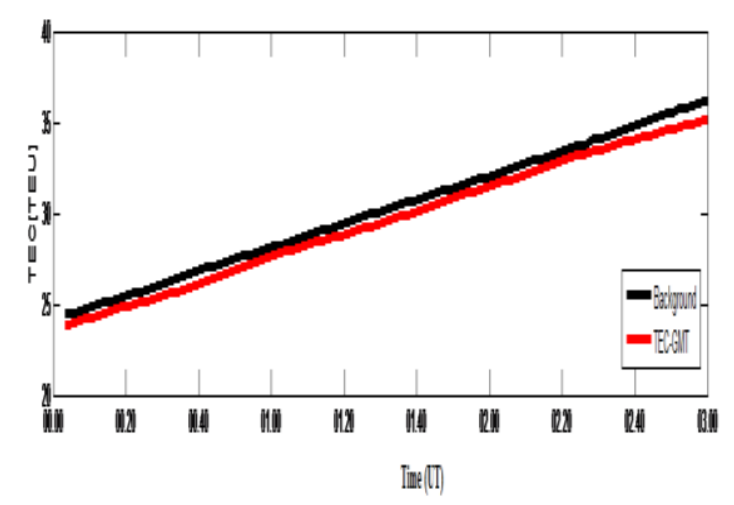

(a)

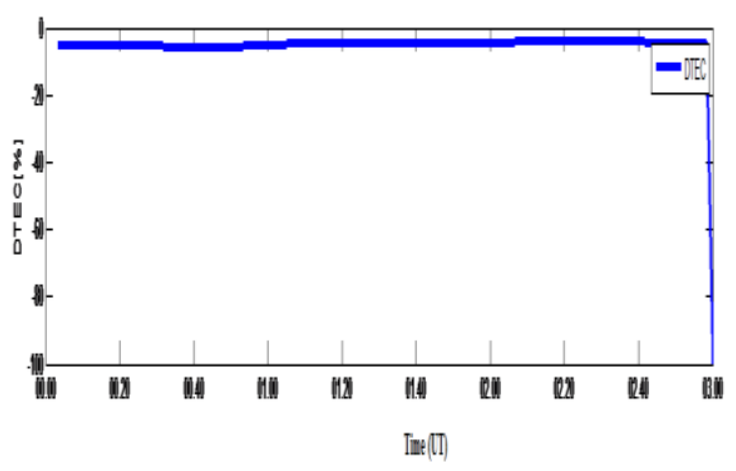

(b)

Gambar 6. (a) Perbandingan nilai TEC GMT dan TEC harian, (b) persentase penurunan nilai TEC GMT terekam oleh satelit 31 .

Gambar 6 (a) menjelaskan persentase penurunan nilai TEC pada satelit 31. Nilai TEC pada saat GMT bisa dikatakan tidak terjadi penurunan dibandingkan dengan nilai TEC harian. Gambar 6 (b) merupakan persentase penurunan nilai TEC pada saat GMT adalah $0 \%$ bahkan pada saat berlangsungnya puncak GMT.

\section{KESIMPULAN}


Kedua stasiun pengamatan yang berada di sekitar lintasan GMT 9 Maret dapat disumpulkan bahwa pada tanggal 8 Maret tidak adanya gangguan di ionosfer. Pada tanggal 9 Maret, kerapatan elektron di ionosfer berkurang, dan pada tanggal 10 Maret adanya gangguan yang disebabkan oleh fenomena GMT 9 Maret 2016. Untuk melihat persentase penurunan nilai GMT dapat dilihat dari satelit - satelit yang melintas pada jalur GMT. Penurunan nilai TEC ionosfer pada saat GMT berkisar antara $40 \%$. Selain itu, nilai TEC pada saat GMT berkurang 5 TECU dibandingkan TEC harian. Fenomena GMT tidak mempengaruhi satelit - satelit yang berada diluar lintasan GMT, Nilai TEC pada saat GMT lebih besar dibandingkan dengan nilai TEC harian. Pada stasiun pengamatan CAMP persentase penurunan nilai TEC $0 \%$, hal ini disebabkan stasiun CAMB berada di luar lintasan GMT.

\section{REFERENSI}

1. Kadarsah \& Daud, A. (2016). Pengaruh Gerhana Matahari Total 9 Maret 2016 Pada Parameter Meteorologi Di Stasiun
Meteorologi 745 Kemayoran. Prosiding Seminar Nasional Sains Antariksa V, Pusat Sains dan Teknologi Atmosfer LAPAN, Auditorium LAPAN, Bandung, 21 April 2016, 1-8.

2. Vita, A. N., Sunardi, B., Sulastri, \& Sakya, A. E. (2016). Pengaruh Gerhana Matahari 09 Maret 2016 Terhadap Kandungan Total Elektron Ionosfer. Prosiding Seminar Nasional Fisika 2017, Universitas Negeri Jakarta, Gedung Fakultas MIPA, Jakarta, 1 Oktober 2017, 4EPA, 51-56.

3. Husin, A., Jiyo, Anggaran, S., Ekawati, S., \& Dear, V. (2016). Analysis Of Ionospheric Irregularities During Total Solar Eclipse 2016 Based On GNSS Observation. Journal of Physics: Conference Series, 771, 012035(1-4).

4. Abidin. (2006). Penentuan Posisi Dengan GPS Dan Aplikasinya. Jakarta: PT Pradnya Paramita.

5. Unawe Indonesia. (2016). Gerhana Matahari Total 9 Maret 2016 Observatorium Bosscha, Lembang, Jawa Barat. Diakses pada 20 Juni 2017, URL: https://bosscha.itb.ac.id/unawe/.

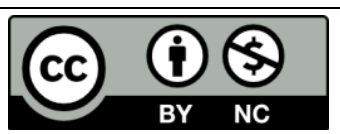

Artikel ini menggunakan lisensi Creative Commons Attribution 4.0 International License 